\title{
A LONGITUDINAL STUDY OF SCHOOL SATISFACTION -MENTAL HEALTH AND SOCIAL SKILLS UPON COLLEGE ADMISSION-
}

\author{
Yuko Ikui \\ Faculty of Humanities, Seisen Jogakuin College (Japan)
}

\begin{abstract}
The university entrance rate in Japan has been increasing over decades. Since 2005, it has finally exceeded fifty percent of high school graduates (Katase, 2007). As the entrance rate has gone up, the number of students who suffers from university maladjustment has also been increasing (Yamada, 2006). In this research, the author examined the possibility of using satisfaction with school life as an indicator to prevent such maladjustment, and conducted a two-year longitudinal study on female college students (four-year college and two-year college). The state of mental health and social skills was examined just after the commencement of the semester in April, and satisfaction with school life (motivation for school life; approval; maladjustment) was examined in the same students three months later in July, and a year later in July.

Based on the results of a $t$-test between 19 students who were in a poor mental health state upon admission and the remaining 162 students, significant statistical differences were found in satisfaction levels in the sophomore year between two groups (Motivation/ Approval $p<.01$; Maladjustment $p<.05$ ). Moreover, among the 19 students with poor mental health, there was no significant change in school satisfaction from freshman to sophomore, although 5 students with relatively higher social skills showed a lower score of Maladjustment $(\mathrm{p}<.05)$ than the other students. Even if students were at risk of poor mental health upon admission, it seems to be safe to assume that acquisition of social skills, possibly through institutional support, will be helpful to increase their resistance to anticipated maladjustment.
\end{abstract}

Keywords: College student, college adjustment, prevention of maladjustment, mental health, social skills.

\section{Introduction}

The university entrance rate in Japan has been increasing over decades. In 2005, the university entrance rate exceeded 50\% of high school graduates (Katase, 2007). As the entrance rate increased, the number of students entering university involuntarily and suffering from university maladjustment also increased (Yamada, 2006). To prevent university maladjustment or drop out, the University Personality Inventory (UPI) was developed in Japan (1966). The UPI is used to check the states of mental health of freshmen in select universities and colleges in Japan (Oka et al., 2015).

Musashi, et al (2013) investigated school satisfaction (Kawamura, 2010), an indicator of students' senses of adjustment to university and mental health. The study revealed a relationship between a low school satisfaction score and the tendency to suffer from depression and social anxiety. Ikui (2018) further investigated the influence of mental health and social skills on university and college admission and on school satisfaction. According to the results, the tendency to suffer from depression and the level of social skills affected the school satisfaction score and motivation to engage in school life after three months. Students whose state of mental health was at risk (i.e. UPI high group) demonstrated a tendency towards a lower motivation to build relationships with new friends and classmates than the other group.

\section{Objectives}

The purpose of this research is to further examine the influence of mental health states and social skills at admission on school adjustment by conducting a longitudinal study. The transition of students'school satisfaction and motivation for school life from freshman to sophomore is investigated through a sample from a college for female students. It will provide a proposal for the support system of a university to relieve maladjustment, especially for students with mental health problems.

\section{Methods}

\subsection{Survey period and participants}

As the first phase of the research, the author implemented the UPI questionnaire (Japan University Health Association, 1966) and KiSS-18 (Kikuchi, 1988/2004) to 239 freshmen during 
the orientation session in April 2017, and 220 students agreed to submit the informed consent form and participate in the research. The second phase of the research was conducted 3 months later, in July 2017, and 237 freshmen took Hyper-QU for university (Kawamura, 2014). After 1 year, the same students completed the second Hyper-QU in July 2018. The informed consent form was handed out to students again. Data from the 180 students who completed all the questionnaires and agreed to participate in the research were used for the analysis.

\subsection{Measurement}

UPI (University Personality Inventory, 1966): The questionnaire comprises 60 items and five lower factors: i) Subjective Symptoms (16 items), ii) Depression (20 items), iii) Social Anxiety (10 items), iv) Obsession (10 items) and v) Positive emotion (4 items). Choose (Yes or No). If the sum score of i) -iv) is greater than 30 , the state of mental health is assessed as high risk and should be given the appropriate support.

KiSS-18 (Kikuchi's Scale of Social skills, 1988/2004): Questionnaire with 18 items that measure the overall social skills for a smooth interpersonal relationship. 5-point Likert Scale.

Hyper-QU (2010: Standardized test comprising three scales-School Satisfaction, Motivation for School Life and Social Skills-measured on a 5-point Likert Scale. In this research, only School Satisfaction and Motivation scale were used for the analysis.

School Satisfaction: This scale comprises 30 items and two lower factors; Approval (how one's existence or behavior is approved by others; 15 items) and Maladjustment (how one experience the sense of maladjustment; 15 items).

Motivation for School Life: Scale comprises 30 items and six lower factors: Relationship with Friend (5 items), Desire to learn (5 items), Relationship with Faculty/Staff (5 items), Support System of College (5 items), Career Consciousness (5 items) and Relationship with Classmate (5 items). In this research, only the total score of this scale was used for the analysis.

\section{Results} April 2017.

Table1 shows the means and standard deviations of UPI/KiSS-18, which was investigated in

Table 1. Dean and SD of UPI (Total/UPI high/low Group) and KISS-18(Total).

\begin{tabular}{|c|c|c|c|c|c|c|c|c|c|}
\hline \multirow{2}{*}{ Scale } & \multirow{2}{*}{\multicolumn{3}{|c|}{ Factor }} & \multicolumn{2}{|c|}{ Total $(N=180)$} & \multicolumn{2}{|c|}{ UPI high G $(N=19)$} & \multicolumn{2}{|c|}{ UPI low $G \quad N=161)$} \\
\hline & & & & $M$ & $S D$ & $M$ & $S D$ & $M$ & $S D$ \\
\hline \multirow[t]{6}{*}{ UPI } & Total & Mental Health) & & 14.7 & 10.58 & 34.9 & 4.85 & 12.3 & 8.09 \\
\hline & & (1) Physical/Mer & bjective Symptoms & 3.6 & 3.06 & 8.5 & 2.54 & 3.1 & 2.59 \\
\hline & & & (2) Depression & 5.7 & 4.51 & 13.6 & 2.70 & 4.7 & 3.51 \\
\hline & & & (3) Social Anxiety & 3.1 & 2.61 & 7.3 & 1.72 & 2.7 & 2.16 \\
\hline & & & (4) Obsession & 2.6 & 2.41 & 6.4 & 1.80 & 2.1 & 2.05 \\
\hline & & & *(5) Positive Items & 1.7 & 1.28 & 0.9 & 1.00 & 1.8 & 1.28 \\
\hline KiSS-18 & Total & \$ocial Skill) & & 56.9 & 11.07 & & & & \\
\hline
\end{tabular}

The cut-off point of the total UPI score is 30. Table1 indicates that all scores in UPI high group are twice as high as that of the UPI low group. To compare school satisfaction scores and motivation for school life in 2017 and in 2018, a paired t test was conducted for the total $(N=180)$, UPI high group $(N=19)$ and UPI low group $(N=161)$. Table2 represents the findings.

Table 2. Mean, SD and t-test score of School Satisfaction Scale and Motivation for School Life Scale for two years.

\begin{tabular}{|c|c|c|c|c|c|c|c|c|c|c|}
\hline \multirow[b]{2}{*}{ Scale } & \multirow[b]{2}{*}{ Factor } & \multicolumn{3}{|c|}{ Total $(N=180)$} & \multicolumn{3}{|c|}{ UPI high $\mathrm{G}(N=19)$} & \multicolumn{3}{|c|}{ UPI low $\mathrm{G}(N=161)$} \\
\hline & & $\begin{array}{c}2017 \\
M(S D)\end{array}$ & $\begin{array}{c}2018 \\
M(S D)\end{array}$ & $t$ & $\begin{array}{c}2017 \\
M(S D)\end{array}$ & $\begin{array}{c}2018 \\
M(S D)\end{array}$ & $t$ & $\begin{array}{c}2017 \\
M(S D)\end{array}$ & $\begin{array}{c}2018 \\
M(S D)\end{array}$ & $t$ \\
\hline \multirow{2}{*}{ School Satisfaction } & Approval & $\begin{array}{c}53.0 \\
(8.41)\end{array}$ & $\begin{array}{c}54.5 \\
(9.62)\end{array}$ & $-2.708 * *$ & $\begin{array}{c}48.3 \\
(11.14)\end{array}$ & $\begin{array}{c}53.6 \\
(8.09)\end{array}$ & 0.204 & $\begin{array}{c}53.4 \\
(8.19)\end{array}$ & $\begin{array}{c}55.3 \\
(8.99)\end{array}$ & $-3.411 * *$ \\
\hline & Maladaptation & $\begin{array}{c}25.4 \\
(8.17)\end{array}$ & $\begin{array}{c}25.1 \\
(8.35)\end{array}$ & 0.518 & $\begin{array}{c}31.3 \\
(9.01)\end{array}$ & $\begin{array}{c}24.5 \\
(7.32)\end{array}$ & 0.614 & $\begin{array}{c}24.9 \\
(7.84)\end{array}$ & $\begin{array}{c}24.6 \\
(8.06)\end{array}$ & 0.403 \\
\hline \multicolumn{2}{|c|}{ Motivation for School Life } & $\begin{array}{c}119.7 \\
(15.90)\end{array}$ & $\begin{array}{c}122.3 \\
(16.72)\end{array}$ & $-2.359 *$ & $\begin{array}{c}111.4 \\
(22.05)\end{array}$ & $\begin{array}{c}120.1 \\
(14.96)\end{array}$ & 0.470 & $\begin{array}{c}120.5 \\
(15.19)\end{array}$ & $\begin{array}{c}123.5 \\
(15.39)\end{array}$ & $-2.796 * *$ \\
\hline
\end{tabular}

The result of the $t$-test reveals significant differences between the scores of approval and motivation for school life in the total group and the UPI low group. This result means that a student who has no obvious mental problem eventually adjusts to school life better as a sophomore than a freshman. 
Among the UPI high group, however, no significant differences are observed in all three factors. Because of the small number of participants, the observed changes of adjustment seem to be the result of the individual differences.

Additionally, students were further divided into two groups - the high social skills group and low social skills group - according to the mean (56.9) of KiSS-18. An independent t test was conducted to compare the high social skill group and low social skill group among each of the UPI high and low groups. The compared scores were school satisfaction (approval and maladaptation) and motivation for school life in the second year. Table 3 presents the representations.

Table 3. Mean, SD and T-test Score of Second Year School Satisfaction and Motivation for School Life by Groups.

\begin{tabular}{|c|c|c|c|c|c|c|c|}
\hline \multirow{3}{*}{ Scale } & \multirow{3}{*}{ Factor } & \multicolumn{3}{|c|}{ UPI high $\mathrm{G}(N=19)$} & \multicolumn{3}{|c|}{ UPI low $\mathrm{G}(N=161)$} \\
\hline & & $\begin{array}{c}\mathrm{K}-18 \text { high } \mathrm{G} \\
\quad(N=5)\end{array}$ & $\begin{array}{c}\mathrm{K}-18 \text { low } \mathrm{G} \\
(N=14)\end{array}$ & $t$ & $\begin{array}{c}\mathrm{K}-18 \text { high } \mathrm{G} \\
\quad(N=89)\end{array}$ & $\begin{array}{c}\mathrm{K}-18 \text { low } \mathrm{G} \\
(N=72)\end{array}$ & $t$ \\
\hline & & $M(S D)$ & $M(S D)$ & & $M(S D)$ & $M(S D)$ & \\
\hline \multirow{2}{*}{ School Satisfaction } & Approval & $52.2(19.01)$ & $46.1(9.44)$ & 0.939 & $57.8(7.91)$ & $52.1(9.29)$ & $4.188 * *$ \\
\hline & Maladaptation & $23.0(6.48)$ & $31.9(9.83)$ & $-1.872 \dagger$ & $22.9(7.17)$ & $26.7(8.62)$ & $-3.085 * *$ \\
\hline \multicolumn{2}{|c|}{ Motivation for School Life } & $118.4(34.22)$ & $108.9(18.57)$ & 0.789 & $126.1(14.91)$ & $119.7(15.90)$ & $2.612 *$ \\
\hline
\end{tabular}

In UPI low group, significant differences are observed between the high social skill group and low social skill group for approval, maladaptation and motivation for school life. Even among the healthy students, students with higher compared with lower social skills naturally adjust to school life after 1 year. In UPI high group, the only significant difference is at maladaptation. Using the skill to build the connection with their supporter (i.e. friends, classmates or teachers), the students who had mental health problems and high social skills at admission could prevent maladaptation.

\section{Conclusions}

The results of this study indicate that the students with mental health problems at admission showed low school satisfaction after 3 months. This tendency continued in the second year. Among this group, however, the maladaptation score of the students who have relatively high social skills decreased compared with the students with low social skills. Thus, a safe assumption is that having higher social skills naturally allows these students to, for example, connect with individuals, rely on others as necessary and share their weakness. Although these students may not be able to feel fully satisfied with or have a sufficient amount of motivation to engage in school life, they might at least be able to feel accepted into the school community.

The methodological limitation of this study is the insufficiency of participants, especially the at-risk freshmen who joined this longitudinal study. Additionally, because this research was conducted at a college for female students, the participants were naturally limited. To increase the number of participants, further research will be conducted widely among various colleges and universities.

\section{References}

Ikui, Y. (2018) The effect of mental health and social skills on satisfaction with school life. Proceedings of the International Psychological Applications Conference and Trends 2018.

Katase, K (2007) The sufferings of university professors in universal era: in the case of Tohoku Gakuin University. Tohoku Gakuin University Educational Research Institute Bulletin. 7, 5-40.

Kawamura, S. (2010) Hyper-QU for university. Toshobunka Company.

Kikuchi, A (1988/2004) Notes on the Researchers Using KiSS-18. Bulletin of the Faculty of Social Welfare, Iwate Prefectual University, 6(2), 41-51.

Japan University Mental Health Association (1966) The handbook of University Personality Inventory. Sozo Publishing.

Musashi, Y., Yamamoto, Y., Shinada, E., Kawamura, S. (2013) The relationship between the satisfaction with school life and the mental health of undergraduates. Japanese Journal of Counselling Science, 45(3), 165-174.

Oka, I., Yoshimura, M., Yamagishi, T. (2015) Forty three years of changes in mental health of Tsuda College freshmen: Results from University Personality Inventory. Tsuda College Departmental Bulletin, 47, 175-195.

Yamada, Y.(2006) Investigation of freshman's adjustment to college life. Journal of Nagoya Bunri University, 6, 29-36. 